\title{
The Retrocorporeal Artery: An Alternative Route for Endovascular Treatment of Spinal Dural Arteriovenous Fistula
}

\author{
Aneesh Mohimen ${ }^{1}$ Santhosh Kumar Kannath ${ }^{2}$ Jayadevan Enakshy Rajan ${ }^{2}$ \\ ${ }^{1}$ Department of Imaging Sciences and Interventional Radiology, Sree \\ Chitra Tirunal Institute of Medical Sciences and Technology, \\ Trivandrum, Kerala, India \\ 2 Department of Imaging Sciences and Interventional Radiology, \\ Neurointervention Center, Sree Chitra Tirunal Institute of Medical \\ Address for correspondence Santhosh Kumar Kannath, MD, PDCC, \\ Department of Imaging Sciences and Interventional Radiology, \\ Neurointervention Center, Sree Chitra Tirunal Institute of Medical \\ Sciences and Technology, Trivandrum 695011, Kerala, India \\ (e-mail: drsanthoshkannath@gmail.com).
} Sciences and Technology, Trivandrum, Kerala, India

J Clin Interv Radiol ISVIR 2017;1:168-170.

\begin{abstract}
Keywords

- spinal dural arteriovenous fistula

- embolization

- retrocorporeal artery

Endovascular transarterial embolization with liquid embolic agents is the primary modality of treatment of spinal dural arteriovenous fistulae. However, adequate distal percolation of the embolic material may not be achieved in all cases due to varying angiographic characteristics, necessitating further surgical treatment. In such situations, the presence of a retrocorporeal branch of the contralateral radicular artery may provide an alternative route to approach and embolization of the fistula. We describe two cases of treatment failure through the primary arterial feeder that was successful embolized through the retrocorporeal artery. The technical detail of this approach is briefly discussed.
\end{abstract}

\section{Introduction}

Endovascular treatment has emerged as the primary treatment option for the management of spinal dural arteriovenous fistula (SDAVF). The goal of endovascular embolization is to achieve embolic penetration into the nidus and proximal segment of the draining vein. Though less invasive, the successful obliteration of fistula is achieved in 70 to $90 \%$ of the patients and recurrence of fistula is observed in as high as 15 to $30 \%$ of the patients. ${ }^{1,2}$ Among the several factors that decide the outcome of endovascular treatment, difficult navigation and inability to place microcatheter close to the fistula remain important concerns that predict successful percolation of embolic agent into the venous side of the fistula. Recently, endovascular approach to fistula through retrocorporeal artery has been described as an alternative route to achieving successful embolization. ${ }^{3}$ We describe two cases of SDAVF that were completely obliterated through retrocorporeal route after an unsuccessful standard endovascular approach.
The relevant anatomy of retrocorporeal artery and the technical nuances are discussed herein.

\section{Case Description}

\section{Case 1}

A 56-year-old woman presented with slowly progressive weakness of the right lower limb in association with burning paresthesias of the right leg and urinary urgency. Clinical examination revealed bilateral asymmetric paraparesis (right $>$ left). Magnetic resonance imaging (MRI) showed long-segment intramedullary hyperintensity involving the lower dorsal cord and the conus with presence of flow voids along the dorsal surface of the cord. The patient underwent spinal angiography, which showed SDAVF with arterial feeder from radicular branch of the right D11 intercostal artery. Under general anesthesia, a $7 \mathrm{~F}$ renal guide catheter (RGC, Medtronics) was placed in the aorta and the right D11 intercostal artery was selectively catheterized using a $4 \mathrm{~F}$ Judkins left coronary catheter (Cordis, Warren, New Jersey, received

January 16, 2017

accepted after revision

May 5, 2017

published online

September 1, 2017
DOI https://doi.org/

$10.1055 / \mathrm{s}-0037-1603823$.

ISSN 2457-0214.
Copyright $\odot 2017$ by Indian Society of

Vascular and Interventional Radiology
License terms

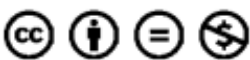


United States). The radicular artery was cannulated using a Marathon microcatheter and Mirage microguidwire (Covidien/Medtronics, Irvine, California, United States). The fistula embolization was performed with $17 \%$ n-butyl cyanoacrylate (n-BCA) without satisfactory antegrade percolation. Subsequent angiogram of left D11 intercostal artery showed the fistula opacification from the left D11 artery via the retrocorporeal artery. The retrocorporeal artery was then cannulated and the microcatheter was advanced into the proximal aspect of the artery. The fistula was completely embolized with $17 \%$ n-BCA (-Fig. 1). Clinical follow-up at 1 year showed significant improvement in neurologic status and magnetic resonance evaluation revealed no recurrence of fistula.

\section{Case 2}

A 65-year-old man presented with paresthesias of both lower limbs along with progressive paraparesis, which acutely worsened to complete paraplegia with loss of all sensations below the level of D8. MRI showed presence of flow voids suggesting the possibility of spinal dural fistula. Spinal angiography revealed SDAVF with arterial feeder from radicular branch of left D12 intercostal artery and he was subsequently planned for endovascular treatment. The left D12 intercostal artery was catheterized using a $4 \mathrm{~F}$ vertebral glide (Terumo, Shizuoka, Japan) diagnostic catheter and the radicular feeder was cannulated using a Marathon/Mirage (Covidien/Medtronics) microcatheter and microguidewire combination. The fistula was subsequently embolized using $15 \%$ NBCA. Significant reflux of embolic material was noted with minimal antegrade percolation. The right D12 intercostal artery angiogram showed the fistulous network opa- cified through the retrocorporeal branch and hence this artery was cannulated and the microcatheter was navigated into its proximal segment. The fistula was embolized using NBCA, achieving complete angiographic fistula obliteration (-Fig. 2). Mild clinical improvement was noted at 6 months; however, no further imaging studies were obtained as patient declined further follow-up.

\section{Discussion}

The successful embolization of SDAVF is determined by the continuous penetration of embolic agent into the nidus and the proximal segment of the draining vein. Among several factors, favorable microcatheter angiographic patterns and concentration of NBCA were identified as significant factors that predict endovascular obliteration of SDAVF. ${ }^{2}$ The appropriate placement of microcatheter close to the fistula is often hindered by small and tortuous feeding arteries. In such instances, the interventionist hopes to achieve adequate venous penetration by varying the concentration of glue or by altering the NBCA ${ }^{4}$ injection technique. Inadequate percolation and proximal occlusion of the feeder precludes further endovascular approaches and necessitates surgical disconnection of the fistula to achieve complete cure. Recently, selective catheterization of retrocorporeal artery and successful embolization have been described as an alternative route in failed conventional endovascular techniques. ${ }^{3}$

The retrocorporeal artery arises from the dorsal spinal branch of the intercostal or lumbar artery and forms a rhomboid-shaped epidural arterial anastomotic network with adjacent and contralateral segmental arteries. ${ }^{5}$ Proximal occlusion of the segmental arteries opens up several

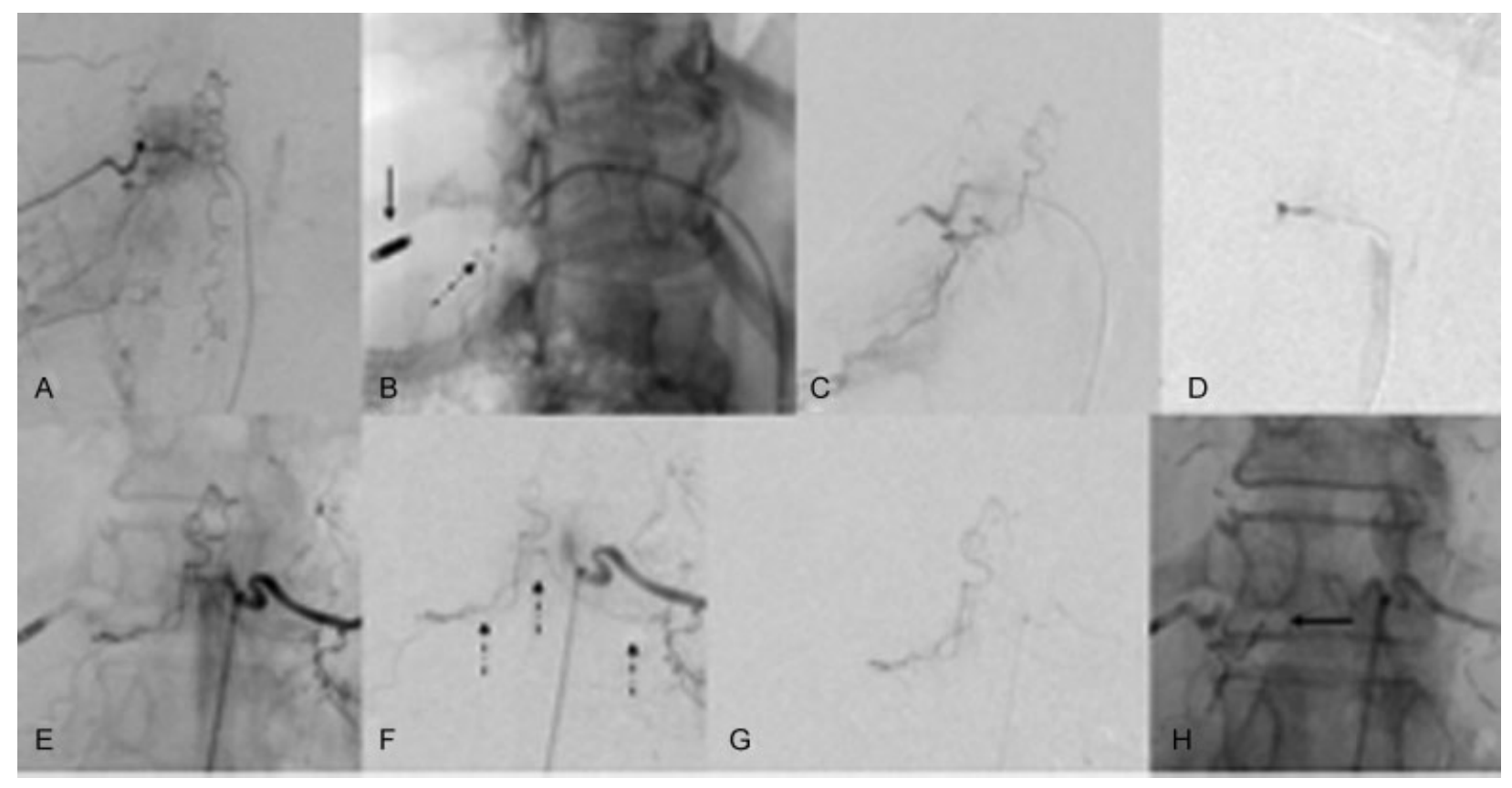

Fig. 1 Patient 1: Right D11 intercostal angiogram (A) shows spinal dural fistula. The microcatheter is placed proximally due to tortuosity (arrow in B) and selective angiogram reveals fistula as well as significant proximal reflux (C). Check angiogram shows occlusion of fistula (D); however, a contralateral intercostal angiogram reconstitutes occluded intercostal artery through retrocorporeal artery (E and arrow in F). Selective angiogram confirms this observation (G), which is occluded by n-BCA. Note glue cast in the nidus and draining vein $(\mathbf{H})$. 


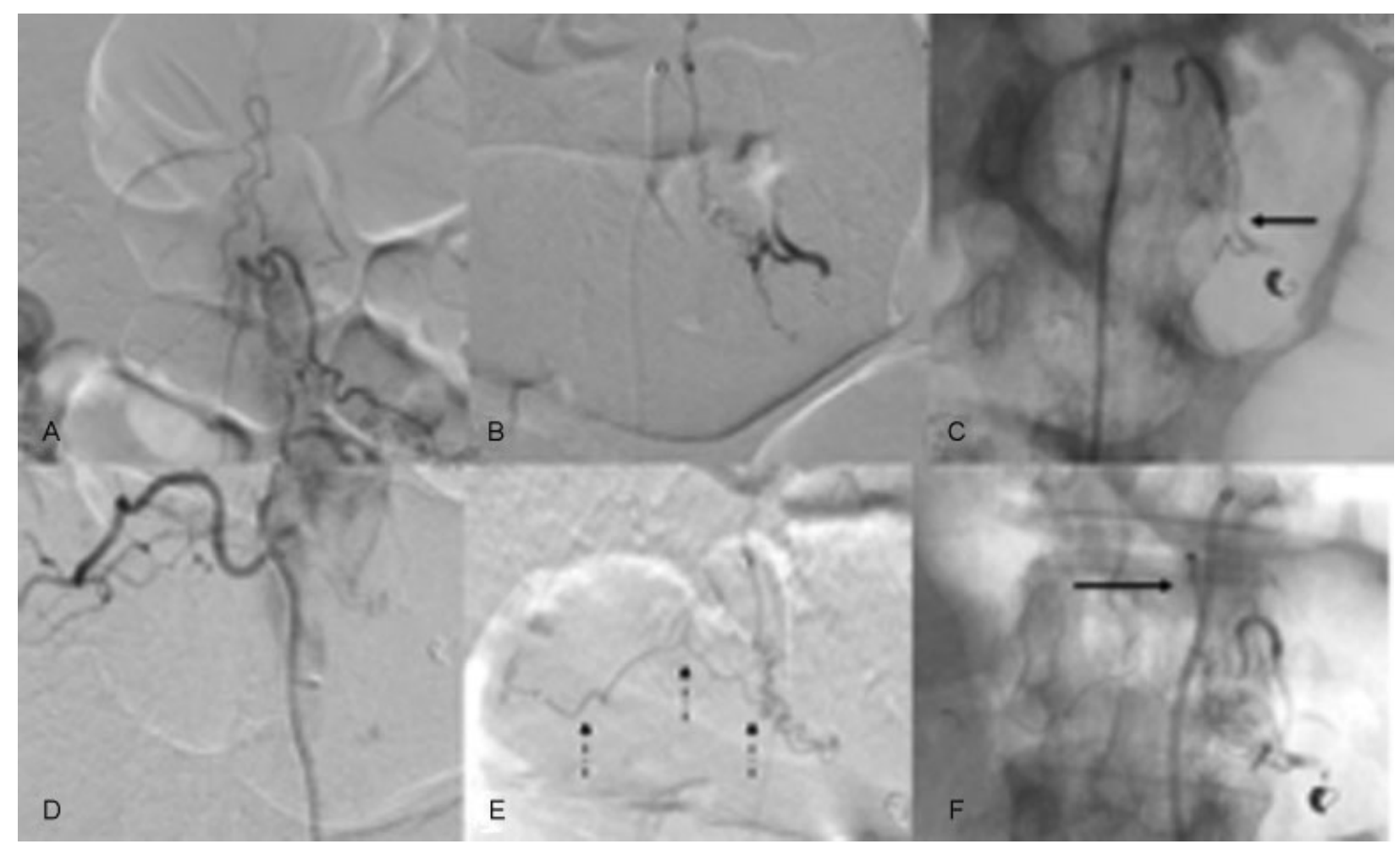

Fig. 2 Patient 2: Intercostal angiogram (A) and selective microcatheter angiogram (B) show spinal dural fistula that was embolized with n-BCA with poor nidal percolation (arrow in C). Intercostal angiogram shows fistula opacification (D) that is clearly demonstrated after microcatheter injection from retrocorporeal artery (interrupted arrows in $\mathbf{E}$ ). Unsubtracted frame (F) shows glue cast in the proximal vein (arrow).

anastomotic communications and reforms the artery distal to occlusion. Because these anastomoses are preformed, immediate reconstitution of the occluded artery can be expected, and if present, it may serve as alternative conduits to access the fistula. The artery is often small, fixed in the epidural space, and has a relatively straight course. Hence, the microguidewire can be advanced sufficiently into the artery to allow it to track along without prolapse into the parent artery. Because of small size of the artery, the microcatheter creates a wedge flow situation and ensures antegrade percolation of embolic agent into the fistula and proximal vein, even if the catheter tip is not close to the site of the fistula. In both the cases demonstrated, embolization was performed through the retrocorporeal artery after initial unsuccessful attempt at embolization through the primary feeding radicular artery. The cannulation of the artery was relatively easy and microcatheter could be placed in proximal segment of the retrocorporeal artery. Complete angiographic embolization of fistula was achieved without significant proximal reflux.

Our report therefore suggests that the retrocorporeal artery is a safe and effective route to tackle fistula that persists following embolization via standard endovascular approach. Careful analysis of adjacent segmental artery angiograms should be performed and presence of this artery must be carefully searched for, so that embolization can be attempted through this route, before considering surgery as the sole treatment option.

\section{Contributions of Authors}

Santhosh Kumar Kannath contributed in concept, design, data analysis, data interpretation, manuscript preparation, and critical revision, Aneesh Mohimen contributed in data analysis, data interpretation, manuscript preparation, and critical revision, and Jayadevan Enakshy Rajan contributed in manuscript preparation and critical revision.

\section{Conflicts of Interest}

The authors have no personal or financial conflict of interest to disclose.

\section{References}

1 Kirsch M, Berg-Dammer E, Musahl C, Bäzner H, Kühne D, Henkes $\mathrm{H}$. Endovascular management of spinal dural arteriovenous fistulas in 78 patients. Neuroradiology 2013;55(03):337-343

2 Su I-C, terBrugge KG, Willinsky RA, Krings T. Factors determining the success of endovascular treatments among patients with spinal dural arteriovenous fistulas. Neuroradiology 2013;55 (11):1389-1395

3 Gory B, Saleme S, Ayoub D, et al. Embolization of spinal dural arteriovenous fistula via the retrocorporeal artery: case report. Neurosurgery 2013;73(2, Suppl Operative):E283-E286

4 Moore C, Murphy K, Gailloud P. Improved distal distribution of n-butyl cyanoacrylate glue by simultaneous injection of dextrose $5 \%$ through the guiding catheter: technical note. Neuroradiology 2006;48(05):327-332

5 Lasjaunias P, Berenstein A, terBrugge KG, et al. Surgical Neuroangiography. Springer Science \& Business Media; 2001 